\title{
Protocolos para a gestão da lesão aguda dos tecidos moles: Revisão Integrativa
}

\author{
Bruno Venâncio Alexandre ${ }^{1}$, Cristina Lavareda Baixinho ${ }^{2}$ e Maria do \\ Céu Sá ${ }^{3}$
}

${ }^{1}$ Unidade de Cuidados Intensivos do Instituto Português de Oncologia, Lisboa, Portugal | brunovenancioalexandre@gmail.com| https://orcid.org/0000-0003-0170-861X

${ }^{2}$ Departamento de Enfermagem de Reabilitação, Escola Superior de Enfermagem de Lisboa, Lisboa; Centro de Investigação, Inovação e Desenvolvimento em Enfermagem de Lisboa (CIDNUR), ciTechaCare, Leiria, Portugal | crbaixinho@esel.pt | http://orcid.org/00000001-7417-1732

${ }^{3}$ Departamento de Enfermagem de Reabilitação, Escola Superior de Enfermagem de Lisboa, Lisboa; ciTechaCare, Leiria, Portugal | ceu.sa@esel.pt | http://orcid.org/0000-0001$8942-6750$

Resumo: Introdução: As entorses da tibiotársica tem uma prevalência elevada na população, nem todas requerem tratamento médico. É consensual que tanto a pessoa como os profissionais de saúde nem sempre baseiam a sua decisão na evidência, com impacto negativo na evolução destas lesões que podem evoluir para a cronicidade. O envolvimento de vários profissionais na reabilitação, com abordagens diferentes, justifica a uniformização de protocolos de atuação. Objetivos: Este estudo tem por objetivos: 1) identificar os acrónimos dos protocolos de atuação para a gestão das lesões dos tecidos moles da articulação tibiotársica e, 2) analisar a evidência dos acrónimos. Métodos: Revisão Integrativa da Literatura orientada pela questão de investigação: "Quais as intervenções preconizadas nos protocolos para a gestão de lesões dos tecidos moles em fase aguda, na população adulta e idosa?", segundo protocolo e critérios de elegibilidade. A pesquisa decorreu entre outubro e dezembro de 2020, nas plataformas EBSCO, B-On, ISI, SCOPUS e JBI. Resultados: Os 11 estudos da amostra bibliográfica são heterogéneos em termo de objetivos e tipo de artigo, possibilitam responder à questão de investigação. Identificaram-se os seguintes acrónimos/protocolos: RICE; PRICE; POLICE; MEAT e PEACE and LOVE. Conclusões: Não há evidência sobre a efetividade destes protocolos para a gestão das lesões dos tecidos moles da articulação tibiotársica. Recomendam-se boas práticas como a aplicação de gelo, elevação do membro e Optimal Loading porque a carga progressiva tem maior probabilidade de restaurar a força e características morfológicas do colagénio.

Palavras-chave: Traumatismos do Pé; Articulação do Tornozelo; Enfermagem; Protocolos; Lesões dos Tecidos Moles.

\section{Protocols for the Management of Acute Soft Tissue Injury: Integrative Review}

Abstract: Ankle sprains are highly prevalent in the population, and not all of them require medical treatment. It is generally agreed that both the individual and health professionals do not always base their decision on evidence, with a negative impact on the evolution of these injuries, which may evolve to chronicity. The involvement of various professionals in rehabilitation, with different approaches, justifies the standardisation of protocols for action. Goals: This study aims to: 1) identify the acronyms of the protocols of action for the management of soft tissue injuries of the ankle joint and,2) analyse the evidence of the acronyms. Methods: Integrative Literature Review guided by the research question: "Which interventions are recommended in protocols for the management of acute soft tissue injuries in adults and elderly people?", according to the protocol and eligibility criteria. The search took place between October and December 2020, in the EBSCO, B-On, ISI, SCOPUS and JBI platforms. Results: (The 11 studies in the bibliographic sample are heterogeneous in terms of objectives and type of article, making it possible to answer the research question. The following acronyms/protocols were identified: RICE; PRICE; POLICE; MEAT and PEACE and LOVE. Conclusions: There is no evidence on the effectiveness of these protocols for the management of soft tissue injuries of the ankle joint. Good practices such as ice application, limb elevation and Optimal Loading are recommended because progressive loading is more likely to restore collagen strength and morphological characteristics

Keywords: Foot injuries; Ankle Joint; Nursing; Protocols; Soft Tissue Injuries. 


\section{Introdução}

As lesões músculoesquléticos são um grave problema de saúde, pela prevalência, risco de recorrência e custos associados ao tratamento e reabilitação (Wever, \& McCollum, 2018). Os traumatismos da articulação tibiotársica (TT) são a causa major da ida aos serviços de urgência (Polzer et al., 2012), 80\% das lesões da TT são entorses, sendo que destas $95 \%$ envolvem principalmente o complexo ligamentar lateral da articulação (Wever, \& McCollum, 2018). Estas mesmas lesões representam $15 \%$ a $20 \%$ das lesões desportivas (Al-Mohrej, \& Al-Kenani, 2017).

Podem ser classificadas em grau I (estiramento/distensão ligamentar), II (ruptura parcial do ligamento) e III (ruptura ligamentar completa) (Polzer et al., 2012). As entorses de grau I e II continuam a ser as lesões mais prevalentes (Wever, \& McCollum, 2018). As lesões de grau I podem ser acompanhadas de edema, alguma sensibilidade, perda funcional mínima, mas sem instabilidade mecânica da articulação (Polzer et al., 2012). Nas lesões de grau II surge dor moderada, edema, sensibilidade moderada nas estruturas envolvidas, com alguma perda de movimento articular e instabilidade leve a moderada (Polzer et al., 2012; Gribble et al., 2016). Nas lesões de grau III a rutura completa é acompanhada de edema e sensibilidade acentuados, hemorragia e incapacidade funcional (Polzer et al., 2012).

Estas lesões afetam significativamente as atividades de vida diária, tornando-se uma causa de absenteísmo tanto escolar, como laboral e, ainda nas atividades físicas e de lazer (Wever, \& McCollum, 2018). Em cerca de $90 \%$ das situações de traumatismo da articulação TT a pessoa retoma a atividade passados 10 dias, sendo que em $72 \%$ dos casos os sintomas persistiram durante seis meses e $45 \%$ não recuperam totalmente em três anos (Gribble et al., 2016; Wever, \& McCollum, 2018).

Punt e Allet (2016) referem que tanto as lesões agudas, como as crónicas têm uma influência negativa nas atividades da vida diária, bem como na percepção da pessoa sobre o seu estado de saúde e funcionalidade.

Al-Mohrej e Al-Kenani, (2017) observaram que o tratamento é geralmente conservador, e que as falhas na reabilitação funcional levam ao desenvolvimento de instabilidade crónica na articulaçao TT. Esta questão tem sido bastante debatida pelos autores que face à diversidade de abordagens têm tentado obter consenso sobre o tratamento destas lesões (Polzer et al., 2012; Gribble et al., 2016; Vuurberg et al., 2018). Conscientes das diferentes abordagens na avaliação, classificação e tratamento dos traumatismos da TT Polzer et al. (2012) conduziram uma revisão sistemática da literatura com o intuito de identificar a melhor evidência, com vista a proporem um algoritmo para o seu diagnóstico e tratamento. Nos resultados do seu estudo sugerem o acrónimo PRICE (protection, rest, ice, compression, and elevation) como uma abordagem para o tratamento conservador, recomendando a cirurgia apenas em casos de instabilidade crónica.

Mais estudos realizados sob esta temática têm proposto a utilização de outros acrónimos, sintetizando os elementos centrais do tratamento conservador com medidas não farmacológicas. Por exemplo, Vuurberg et al. (2018) na atualização de uma guideline clínica para o diagnóstico, tratamento e prevenção das lesões da TT analisam o protocolo RICE (Rest, Ice, Compression, Elevation) e observam que a eficácia desta combinação é questionável. Apesar de a crioterapia e o uso de compressão terem sido objeto de numerosas pesquisas, há pouca evidência para a sua eficácia na redução dos sintomas associados a lesões agudas dos tecidos moles da TT (Vuurberg et al., 2018).

Algumas situações de entorse, sobretudo de grau I, acabam por não ser observadas pela equipa médica. Um documento de consenso sobre a atuação nestas situações observa que, nos casos em que se recorre a uma ajuda especializada, $90 \%$ a gestão das mesmas não é a mais adequada (Gribble et al., 2016). Na maioria das situações de grau I a pessoa opta por um tratamaneto caseiro sem recurso a serviços de saúde, podendo aumentar o tempo de recuperação e o risco de lesões crónicas e de recorrência. 
Consideramos que a utilização dos acrónimos tem potencialidades tanto para a formação dos profissionais de saúde, melhorando e uniformizando a atuação face às lesões agudas dos tecidos moles da articulação TT, como para a educação da própria população sobre os primeiros socorros numa situação de entorse da TT. Isto porque existe uma diversidade de profissionais que podem diagnosticar, aconselhar, encaminhar e até oferecer tratamentos para este tipo de lesão, com base na sua educaçao, treino, desenvolvimento profissional continuo e existência de guidelines, estes profissionais podem ser: médicos, enfermeiros, fisioterapeutas, farmacêuticos comunitários, técnicos de emergência e até treinadores desportivos (Green, Wilson, Martin \& Fallon, 2019).

Face ao exposto, são objetivos deste estudo: 1) identificar os acrónimos dos protocolos de atuação para a gestão das lesões dos tecidos moles da articulação tibotársica e, 2) analisar a evidência dos acrónimos.

\section{Metodologia}

A presente Revisão Integrativa da Literatura (RIL) foi orientada pela seguinte questão de investigação: "Quais as intervenções preconizadas nos protocolos para a gestão de lesões dos tecidos moles em fase aguda, na população adulta e idosa?" elaborada utilizando a mnemónica PICo (população, fenómeno de interesse e contexto) (Souza, Silva, \& Carvalho, 2010; Sousa, Marques-Vieira, Severino, \& Antunes, 2017).

Recorreu-se a um protocolo, com seis etapas, para operacionalizar a pesquisa (Souza, Silva, \& Carvalho, 2010; Sousa, et al., 2017). Após a definição da questão de pesquisa, estabeleceram-se os critérios de elegibilidade para os estudos (Tabela 1). Esta opção metodológica possibilitou estreitar os intervalos de confiança, facilitar a comparação dos trabalhos, interpretação dos dados e aumentar a precisão dos resultados.

Tabela 1. Critérios de elegibilidade para a amostra bibliográfica. Lisboa, 2020.

\begin{tabular}{|c|c|c|}
\hline & Critérios de inclusão & $\begin{array}{l}\text { Critérios de } \\
\text { exclusão }\end{array}$ \\
\hline \multirow{5}{*}{ Tipo de artigos } & Estudos primários & \multirow{5}{*}{$\begin{array}{l}\text { Literatura } \\
\text { Cinzenta }\end{array}$} \\
\hline & Estudos secundários & \\
\hline & Artigos de opinião, & \\
\hline & $\begin{array}{l}\text { Relatos de experiência } \\
\text { e editoriais em revistas } \\
\text { com peer review }\end{array}$ & \\
\hline & Guidelines clínicas & \\
\hline Participantes & $\geq 18$ anos & $0-18$ anos \\
\hline \multirow[t]{2}{*}{ Fenómeno } & \multirow{2}{*}{$\begin{array}{l}\text { Lesões dos tecidos } \\
\text { moles em fase aguda }\end{array}$} & $\begin{array}{l}\text { Luxações e/ou } \\
\text { fraturas }\end{array}$ \\
\hline & & Lesões crónicas \\
\hline
\end{tabular}

Os descritores Mesh/DeCS utilizados na pesquisa, efetuada entre os meses de outubro a dezembro de 2020, foram: (acute soft tissue; injury or traumatic injury or musculoskeletal; trauma or musculoskeletal disorders or skeletal muscle healing); and (guidelines or protocol or acronym); and (management or intervention or rehabilitation or optimal loading) and nurs*.

A pesquisa foi realizada nas bases de dados disponíveis nos motores de busca da EBSCO, B-On, Internacional Scientific Indexing (ISI), SCOPUS e Joanna Briggs Institute (JBI), a partir dos critérios de inclusão e exclusão previamente definidos. 
Para além das restrições temporais foram introduzidos outros filtros: Full Text; Idiomas: português, espanhol e inglês. A revisão da literatura prévia à RIL permitiu constatar que poucos estudos exploram protocolos e acrónimos para a reabilitação das lesões dos tecidos moles da TT, por isso e face à especificidade da revisão optou-se pelo limite temporal de 2010 a 2020.

A pesquisa foi conduzida através de uma investigação, seleção e extração de dados por dois investigadores independentes. Construiu-se uma tabela Excel para o registo do título do artigo/obra; autor(es), ano de publicação, tipo de artigo; objetivo(s), método e técnicas; nível de evidência e principais resultados/conclusões.

Identificaram-se 416 artigos na pesquisa, com os descritores supracitados. A leitura do título possibilitou a identificação de 7 artigos repetidos. A leitura do resumo permitiu excluir 385 estudos que não respeitavam os critérios de elegibilidade predefinidos. Leram-se na íntegra 24 artigos, foram rejeitados 13 artigos por não responderem à questão de investigação. Os 11 artigos finais contemplam a amostra bibliográfica final (Figura 1).

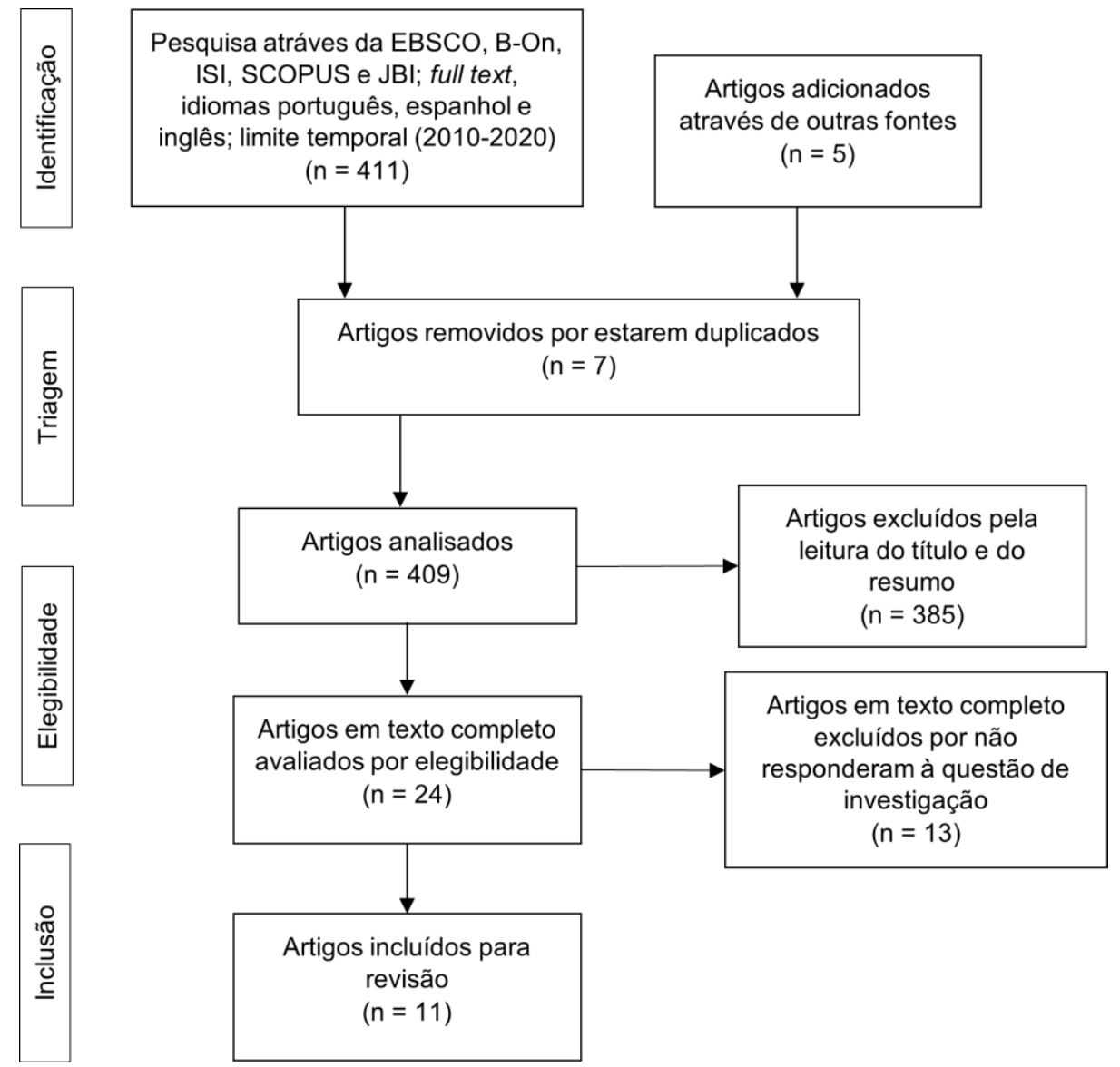

Fig. 1. Fluxograma de seleção dos artigos, segundo as recomendações PRISMA. Lisboa; Portugal. 2020.

A análise dos estudos e extração do conteúdo, para uma tabela Excel, foi efetuada por dois investigadores independentemente e posteriormente aferida pelos autores. 


\section{Resultados}

Os 11 estudos da amostra bibliográfica (Tabela 2) não são homogéneos, têm objetivos e desenhos de estudo diferentes dificultando a comparação dos resultados. Todavia as diferenças da sua interpretação permitem dar resposta à questão de investigação e aos objetivos do estudo. A referir que alguns estudos e documentos de consenso apresentam outros resultados, para além, do acrónimo. Todavia a sua importância, em função dos objetivos da RIL, extraímos só o que aos acrónimos dizia respeito.

Os acrónimos que foram realçados nos estudos elegíveis para esta RIL são: RICE (AIMohrej \& Al-Kenani, 2016; Roosen et al., 2013; Vuurberg et al., 2018; Bekerom et al., 2012; Scialoia \& Swartzendruber, 2020; Lefebvre \& Hatch, 2016); PRICE (Polzer et al., 2012; Beakley, Glasgow \& MacAuley, 2012; Bleakley, 2013); POLICE (Beakley, Glasgow \& MacAuley, 2012; Bleakley, 2013); MEAT (Scialoia \& Swartzendruber, 2020) e PEACE and LOVE (Dubois \& Esculier, 2020).

O ICE corresponde a gelo (I), compressão (C) e elevação (E), o RICE repete esta sequência acrescentando-Ihe o repouso $(R)$, ao qual é adicionado a proteção $(P)$ pelo PRICE. Com o POLICE observamos uma alteração de paradigma com a substituição do repouso pelo optimal loading $(\mathrm{OL})$, mantendo o acrónimo com o resto dos constituintes já descritos. O MEAT apesar de surgir referenciado em apenas um dos estudos selecionados, parece-nos merecer ser referido uma vez que se mostrou ser uma alternativa oposta ao RICE. O MEAT representa assim: movimento (M), exercício $(E)$, analgesia $(\mathrm{A})$ e tratamento $(\mathrm{T})$.

Por fim, enunciamos o acrónimo PEACE and LOVE constituído pela proteção $(\mathrm{P})$, elevação $(E)$, evitar anti-inflamatórios $(A)$, compressão $(C)$, educação $(E)$, carga $(L)$, otimismo $(\mathrm{O})$, vascularização $(\mathrm{V})$, exercício $(\mathrm{E})$.

Tabela 2. Estudos constituintes da amostra bibliográfica, Lisboa; Portugal. 2020.

\begin{tabular}{|c|c|c|c|}
\hline $\begin{array}{c}\text { Autor(es), ano. } \\
\text { País }\end{array}$ & $\begin{array}{l}\text { Tipo de } \\
\text { estudo }\end{array}$ & $\begin{array}{l}\text { Objetiv } \\
\text { o(s) }\end{array}$ & Resultados \\
\hline $\begin{array}{l}\text { E1: Al-Mohrej \& } \\
\text { Al-Kenani, } 2016 . \\
\text { Reino Unido }\end{array}$ & $\begin{array}{l}\text { Revisão } \\
\text { Literatura }\end{array}$ & $\begin{array}{l}\text { Caracterizar o } \\
\text { tema. } \\
\text { Discutir o tipo } \\
\text { de abordagem } \\
\text { (conservadora } \\
\text { ou cirúrgica) }\end{array}$ & $\begin{array}{l}\text { RICE - a realizar nos primeiros } 2-3 \\
\text { dias. Fornecendo muletas (R); imersão } \\
\text { em gelo durante } 20 \text { minutos a cada } 2-3 \\
\text { horas (I); aplicação de uma banda } \\
\text { flexível (C); elevar acima do coração } \\
\text { (E). }\end{array}$ \\
\hline $\begin{array}{l}\text { E2: Polzer et al., } \\
\text { 2012. Itália }\end{array}$ & $\begin{array}{l}\text { Revisão } \\
\text { Sistemática } \\
\text { da } \\
\text { Literatura }\end{array}$ & $\begin{array}{l}\text { Classificar as } \\
\text { evidências e } \\
\text { desenvolver } \\
\text { um algoritmo } \\
\text { para } \\
\text { diagnóstico e } \\
\text { tratamento das } \\
\text { lesões agudas } \\
\text { do tornozelo. }\end{array}$ & $\begin{array}{l}\text { PRICE - a realizar nos primeiros } 3-5 \\
\text { dias. Recurso a uma banda elástica, } \\
\text { anti-inflamatórios não esteroides } \\
\text { durante 3-7 dias. }\end{array}$ \\
\hline $\begin{array}{l}\text { E3: Roosen et al., } \\
\text { 2013. Bélgica }\end{array}$ & Guideline & $\begin{array}{l}\text { Protocolar } 0 \\
\text { diagnóstico e } \\
\text { tratamento das } \\
\text { entorses } \\
\text { laterais agudas } \\
\text { do tornozelo. }\end{array}$ & $\begin{array}{l}\text { RICE - Mover o tornozelo apenas } \\
\text { dentro do limite da dor nos primeiros } \\
\text { dias, desaconselham o repouso } \\
\text { absoluto }(\mathrm{R}) \text {; aplicação de gelo }\left(0-7^{\circ} \mathrm{C}\right) \text {, } \\
4-6 \text { vezes/dia, não utilizar packs de } \\
\text { gelo (I); aplicar uma banda elástica nas } \\
\text { primeiras } 24 \text { h e após uma meia elástica } \\
\text { (C); elevar a perna nos primeiros dias } \\
\text { para assegurar a redução do edema } \\
\text { (E). }\end{array}$ \\
\hline
\end{tabular}




\begin{tabular}{|c|c|c|c|}
\hline $\begin{array}{c}\text { Autor(es), ano. } \\
\text { País }\end{array}$ & $\begin{array}{l}\text { Tipo de } \\
\text { estudo }\end{array}$ & $\begin{array}{l}\text { Objetiv } \\
\text { o(s) }\end{array}$ & Resultados \\
\hline $\begin{array}{l}\text { E4: Vuurberg et } \\
\text { al., 2018. Reino } \\
\text { Unido }\end{array}$ & Guideline & $\begin{array}{l}\text { Facilitar a } \\
\text { uniformidade } \\
\text { do diagnóstico } \\
\text { e tratamento } \\
\text { da lesão aguda } \\
\text { da entorse } \\
\text { lateral do } \\
\text { tornozelo. }\end{array}$ & $\begin{array}{l}\text { RICE - não há evidência de que este } \\
\text { sozinho tenha qualquer influência } \\
\text { positiva na dor, edema ou } \\
\text { funcionalidade da pessoa. }\end{array}$ \\
\hline $\begin{array}{l}\text { E5: Bekerom, } \\
\text { Struijs, } \\
\text { Blankevoort, } \\
\text { Welling, Dijk \& } \\
\text { Kerkhoffs, } 2012 . \\
\text { EUA }\end{array}$ & $\begin{array}{l}\text { Revisão } \\
\text { Sistemática } \\
\text { da } \\
\text { Literatura }\end{array}$ & $\begin{array}{l}\text { Analisar a } \\
\text { eficácia da } \\
\text { aplicação da } \\
\text { terapia RICE, } \\
\text { quando } \\
\text { iniciada dentro } \\
\text { das } 72 \text { horas } \\
\text { após a entorse } \\
\text { do tornozelo. }\end{array}$ & $\begin{array}{l}\text { RICE - As evidências disponíveis nos } \\
\text { ensaios clínicos randomizados são } \\
\text { insuficientes para determinar a eficácia } \\
\text { relativa da terapia RICE nas entorses } \\
\text { agudas do tornozelo no adulto. }\end{array}$ \\
\hline $\begin{array}{l}\text { E6: Beakley, } \\
\text { Glasgow } \quad \& \\
\text { MacAuley, } 2012 . \\
\text { EUA }\end{array}$ & Editorial & $\begin{array}{l}\text { Discutir a } \\
\text { atualidade do } \\
\text { acrónimo } \\
\text { PRICE }\end{array}$ & $\begin{array}{l}\text { PRICE - O repouso deve ser de } \\
\text { duração limitada e restrito } \\
\text { imediatamente após o trauma. Pode } \\
\text { ser prejudicial e inibe a recuperação. } \\
\text { POLICE - Optimal Loading a carga } \\
\text { progressiva tem maior probabilidade de } \\
\text { restaurar a força e características } \\
\text { morfológicas do colagénio. }\end{array}$ \\
\hline $\begin{array}{l}\text { E7: Scialoia \& } \\
\text { Swartzendruber, } \\
\text { 2020. EUA }\end{array}$ & $\begin{array}{l}\text { Revisão da } \\
\text { Literatura }\end{array}$ & $\begin{array}{l}\text { Analisar as } \\
\text { evidências } \\
\text { disponíveis na } \\
\text { literatura para } \\
\text { elucidar porque } \\
\text { é que o } \\
\text { protocolo RICE } \\
\text { não é um } \\
\text { método } \\
\text { confiável para } \\
\text { melhorar o } \\
\text { processo de } \\
\text { recuperação } \\
\text { de lesões } \\
\text { musculo - } \\
\text { esqueléticas } \\
\text { agudas. }\end{array}$ & $\begin{array}{l}\text { RICE - O uso desta técnica para } \\
\text { acelerar o processo de recuperação é } \\
\text { inequivocamente um mito. } \\
\text { MEAT - Foi proposto como uma } \\
\text { alternativa mais ideal, abordando de } \\
\text { uma forma mais eficaz as discrepâncias } \\
\text { em torno do protocolo RICE. }\end{array}$ \\
\hline $\begin{array}{l}\text { E8: Dubois \& } \\
\text { Esculier, } 2020 . \\
\text { Reino Unido }\end{array}$ & Editorial & $\begin{array}{l}\text { Divulgar } \\
\text { acrónimo } \\
\text { PEACE } \\
\text { LOVE and } \\
\text { justificar a } \\
\text { suas } \\
\text { vantagens em } \\
\text { relação ao ICE, } \\
\text { RICE, PRICE e } \\
\text { POLICE }\end{array}$ & $\begin{array}{l}\text { ICE, RICE, PRICE e POLICE - focam- } \\
\text { se no tratamento agudo, ignorando os } \\
\text { estádios subagudos e crónicos da } \\
\text { cicatrização dos tecidos. } \\
\text { PEACE AND LOVE - engloba o } \\
\text { continuum da reabilitação desde o } \\
\text { cuidado imediato até à gestão posterior. } \\
\text { Delineando a importância de educar as } \\
\text { pessoas e abordar os fatores } \\
\text { psicossociais para melhorar a } \\
\text { recuperação. Os anti-inflamatórios } \\
\text { podem ter efeitos potencialmente } \\
\text { prejudiciais na cicatrização ideal dos } \\
\text { tecidos. }\end{array}$ \\
\hline
\end{tabular}




\begin{tabular}{|c|c|c|c|}
\hline $\begin{array}{c}\text { Autor(es), ano. } \\
\text { País }\end{array}$ & $\begin{array}{l}\text { Tipo de } \\
\text { estudo }\end{array}$ & $\begin{array}{l}\text { Objetiv } \\
\text { o(s) }\end{array}$ & Resultados \\
\hline $\begin{array}{l}\text { E9: Lefebvre \& } \\
\text { Hatch, 2016. EUA }\end{array}$ & Protocolo & $\begin{array}{l}\text { Sistematizar a } \\
\text { evidência }\end{array}$ & $\begin{array}{l}\text { RICE - a maior parte dos argumentos } \\
\text { para o uso deste acrónimo ou dos seus } \\
\text { componentes individuais são } \\
\text { amplamente baseados em ensaios } \\
\text { clínicos de baixa qualidade e em } \\
\text { estudos de laboratório com } \\
\text { participantes ilesos ou modelos } \\
\text { animais. }\end{array}$ \\
\hline $\begin{array}{lr}\text { E10: } & \text { Bleakley, } \\
\text { 2013. } & \text { Reino } \\
\text { Unido } & \end{array}$ & $\begin{array}{l}\text { Revisão da } \\
\text { Literatura }\end{array}$ & $\begin{array}{l}\text { Fornecer uma } \\
\text { atualização } \\
\text { sobre a base } \\
\text { científica para } \\
\text { o uso do } \\
\text { PRICE e dos } \\
\text { seus } \\
\text { componentes, } \\
\text { e conselhos } \\
\text { práticos para a } \\
\text { implementação } \\
\text { clínica. }\end{array}$ & $\begin{array}{l}\text { PRICE - Grande parte da base da } \\
\text { evidência é composta por estudos } \\
\text { científicos básicos e evidências } \\
\text { observacionais, em vez de evidências } \\
\text { clínicas. } \\
\text { Substituído o rest (R) por optimal } \\
\text { loading, originando o acrónimo POLICE } \\
\text { em vez de PRICE }\end{array}$ \\
\hline $\begin{array}{l}\text { E11: Bleakley et } \\
\text { al., 2010. Reino } \\
\text { Unido }\end{array}$ & $\begin{array}{l}\text { Revisão da } \\
\text { Literatura }\end{array}$ & $\begin{array}{l}\text { Rever a } \\
\text { eficácia clínica } \\
\text { e os } \\
\text { fundamentos } \\
\text { fisiopatológicos } \\
\text { para o uso do } \\
\text { PRICE na } \\
\text { lesão aguda de } \\
\text { tecidos moles. }\end{array}$ & $\begin{array}{l}\text { PRICE - Realizar descarga sobre o } \\
\text { tecido na fase aguda após a lesão, } \\
\text { evitando movimentos no plano da } \\
\text { lesão. A carga progressiva deve ser } \\
\text { iniciada após a fase aguda. Depois de } \\
\text { qualquer elevação, voltar a colocar a } \\
\text { parte do corpo para uma posição } \\
\text { dependente da gravidade, } \\
\text { gradualmente. }\end{array}$ \\
\hline
\end{tabular}

\section{Discussão}

A crioterapia enquanto intervenção, está presente tanto no ICE, como no RICE, PRICE e POLICE. Esta é tida como uma intervenção de relevo no controlo e redução do edema, assim como na dor decorrente da lesão dos tecidos moles da TT. As recomendações da sua utilização dispersam desde a imersão em gelo durante 20 minutos de 2-3h, com o objetivo de manter a temperatura da TT nos $12^{\circ} \mathrm{C}$ (Al-Mohrej \& Al-Kenani, 2016). Contrapondo esta prescrição existe a recomendação da aplicação de gelo durante 10 minutos, com um intervalo de outros 10 minutos entre uma nova aplicação do mesmo tempo a cada duas horas. Esta modalidade demonstra um benefício adicional, em termos de dor, quando comparada com a aplicação padrão de 20 minutos, durante a primeira semana pós lesão (Lefebvre \& Hatch, 2016). Recomendação apoiada também por Bleakley et al. (2010), que prescreve a aplicação de gelo durante 5 a 15 minutos, uma vez que são atingidos níveis melhores de analgesia. A utilização do gelo combinado com o exercício mostra efeitos positivos no edema em comparação com a aplicação de quente, mas quando utilizado isoladamente não mostra efeitos no aumento da funcionalidade, nem da redução do edema e da dor (Kerkhoffs et al., 2012). Em relação à aplicação do gelo é bastante limitada a existência de evidência consolidada acerca dos seus efeitos, no entanto, não existe evidência que diga para não ser utilizado (Wever et al., 2018).

A nível fisiopatológico o repouso potencia a congestão de resíduos metabólicos provenientes da lesão, atrasando a conclusão do processo inflamatório, e consequentemente o processo de cicatrização e remodelação (Scialoia \& Swartzendruber, 2020). Ainda a este nível, os mesmos autores afirmam que a atividade após uma lesão musculoesquelética irá inibir a miostatina, proteína que limita o crescimento muscular, reduzindo a possibilidade de atrofia muscular (Scialoia \& Swartzendruber, 2020). 
Também Bleakley et al. (2010) afirmam que períodos longos de repouso, 2 a 3 semanas, são prejudiciais, dado que promovem mudanças adversas na biomecânica e morfologia do tecido lesionado. Posto isto, é recomendada a realização de carga sobre a TT, dado que mesmo períodos curtos de descarga irão resultar em alterações negativas na força muscular, na morfologia do tecido, nas propriedades biomecânicas e na resistência à tração (Bleakley, 2013). Estes dados levam-nos a crer que períodos de repouso após uma lesão musculoesquelética aguda não promovem o processo de recuperação (Scialoia \& Swartzendruber, 2020). A aplicação de carga precoce e progressiva sobre o tecido lesado mostra-se uma intervenção com maiores benefícios do que o repouso (Bleakley, 2013), dado que tem maior probabilidade de restaurar a resistência e as características morfológicas dos tecidos compostos por colagénio, ou seja, conjuntivos como tecido ósseo e cartilaginoso (Bleakley et al., 2010).

Em lesões de maior gravidade é por vezes prescrito a imobilização da TT, com recurso ao gesso, no entanto, um período longo de imobilização (mínimo de 4 semanas) é menos eficaz quando comparado com outros tratamentos funcionais, quando necessária recomenda-se um período máximo de 10 dias para a redução da dor e do edema (Kerkhoffs et al., 2012).

O acrónimo RICE, presente também no PRICE, é mencionado em todos os 11 estudos incluídos nesta RIL, este apresenta-se pela defesa do repouso como intervenção essencial para a recuperação após lesão da TT. No entanto, quando este é aplicado de forma isolada não apresenta mais benefícios, quando comparado com a sua utilização em conjunto com uma mobilização antero-posterior e manipulação da TT, dado que esta última demonstra uma melhora significativa na amplitude do movimento (Roosen et al., 2013).

O uso dos anti-inflamatórios, não é consensual, Polzer et al. (2012) afirmam que estes conduzem a uma redução significativa da dor, o que conduz a uma recuperação mais rápida, recomendando o seu uso durante 3 a 7 dias juntamente com o uso da crioterapia. No entanto, as várias fases do processo inflamatório ajudam na cicatrização dos tecidos lesados, o que conduz à premissa que a inibição da inflamação através de medicação pode afetar negativamente a cicatrização dos tecidos a longo prazo (Dubois \& Esculier, 2020). O mesmo autor acrescenta que também o gelo pode ter este efeito negativo, dado que interrompe o processo inflamatório e a revascularização, retardando a infiltração de neutrófilos e macrófagos (Dubois \& Esculier, 2020).

O optimal loading, um conceito que surge primeiramente no acrónimo POLICE e se mantém no PEACE and LOVE, marcando a preferência por estes dois, comparativamente com os anteriores, nomeadamente o RICE e o PRICE. O optimal loading visa substituir o repouso por um programa de reabilitação equilibrado, onde a atividade é iniciada precocemente, assim como a recuperação (Beakley, Glasgow \& MacAuley, 2012; Bleakley, 2013). A questão essencial para a aplicação desta intervenção prende-se com: o que é a carga ideal? Dado ao carácter ímpar de cada lesão não são apresentadas recomendações da carga a aplicar, no entanto, esta deve ser imposta tendo em conta o stress colocado sobre o tecido lesado, o tipo de tecido e a região anatómica. (Beakley, Glasgow \& MacAuley, 2012) No início desta intervenção devem ser realizados períodos curtos de carga com períodos mais longos de repouso (Bleakley, 2013). Ao aplicar o optimal loading sem exacerbar a dor estar-se-á a promover a cicatrização, a remodelação e a aumentar a tolerância dos tecidos, assim como a capacidade de resistência dos tendões, músculos e ligamentos (Dubois \& Esculier, 2020).

Dados aos resultados apresentados e argumentos para os constituintes de cada acrónimo, cremos que o acrónimo com as intervenções justificadas por uma evidência de maior qualidade e com menos argumentos que refutem a sua utilização é o acrónimo POLICE. Este consenso não provém da referência ao acrónimo em si, mas sim da análise dos seus constituintes. 


\section{Conclusões}

Avaliando os resultados obtidos dos artigos selecionados concluímos que será pertinente desaconselhar o uso dos acrónimos ICE, RICE e PRICE dados os argumentos utilizados, principalmente na rejeição do repouso como parte integrante do processo de reabilitação da lesão aguda da TT. Em suma, e tendo em conta o apresentado na discussão acerca dos benefícios da mobilização precoce, concluímos que esta deve ser iniciada o mais cedo possível. Dada a recomendação de dar tempo para a aplicação do gelo controlar a dor e o edema, visando a melhoria e manutenção da amplitude do movimento, minimizando o risco de rigidez articular e atrofia muscular. Ou seja, a mobilização da TT deve ser realizada, nos primeiros dias, dentro do limite da dor, desencorajando o repouso absoluto e por isso mesmo, aconselhamos os acrónimos referidos.

A análise efetuada ao conteúdo dos artigos foi suportada pelos princípios da análise de conteúdo, o que confere rigor e validade ao presente estudo. Todavia a presente RIL tem subjacentes limitações ao nível da qualidade de evidência selecionada, sendo composta por apenas duas revisões sistemáticas da literatura e nenhum estudo controlado randomizado ou estudo clínico. Outro dado que contribui para uma análise menos profunda da questão de investigação é o fato de esta RIL incorporar na sua maioria estudos que recaem sobre o acrónimo RICE, não tendo assim uma amostra variada e igualitária para todos os acrónimos.

Posto isto, as sugestões que fazemos para investigações futuras são a realização de ensaios clínicos e estudos controlados randomizados acerca da utilização do acrónimo POLICE e PEACE and LOVE. Com o intuito de justificar ou não a pertinência dos mesmos, quando utilizados os seus constituintes em conjunto, ao invés de uma análise isolada de cada um ou o estudo dos mesmos através de estudos em animais e/ou contextos laboratoriais. Questões como a utilização ou não de anti-inflamatórios, o recurso à compressão e crioterapia parecem-nos também questões que necessitam de ser esclarecidas através deste tipo de estudos que sugerimos.

\section{Referências}

Al-Mohrej, O.A. \& Al-Kenani N.S. (2017). Acute ankle sprain: conservative or surgical approach? EFORT Open Reviews, 13, 1(2),34-44. doi: https://doi.org/10.1302/2058-5241.1.000010.

Baixinho, C.L., Presado, M.H., \& Ribeiro, J. (2019). Qualitative research and the transformation of public health. Ciência \& Saúde Coletiva; 24 (5)1583-1583. https://doi.org/10.1590/141381232018245.05962019

Bekerom, M.P.J., Struijs, P.A.A., Blankevoort, L., Welling, L., Dijk, N., \& Kerkhoffs, G.M.M.J. (2012) What Is the Evidence for Rest, Ice, Compression, and Elevation Therapy in the Treatment of Ankle Sprains in Adults? Journal of Athletic Training, 47(4), 435-443. doi: https://doi.org/10.4085/1062-6050-47.4.14

Bleakley, C.M. (2013) Acute Soft Tissue Injury Management Uodate. Sportex Medicine, 58, 16-19.

Bleakley, C.M., Glasgow, P., \& MacAuley, D.C. (2012). PRICE needs updating, should we call the POLICE? British Journal of Sports Medicine, 46(4), 220-221. doi: https://doi.org/10.1136/bjsports-2011-090297

Bleakley, C.M., Glasgow, P.D., Phillips, N., Hanna, L., Callaghan, M.J., Davison, G.W., ..., Delahunt, E. (2010). Acute Management of Soft Tissue Injuries. Sheffield: Association of Chartered Physiotherapists in Sports and Exercise Medicine.

Dubois, B., \& Esculier, J.F. (2020). Soft-tissue injuries simply need PEACE and LOVE. British Journal of Sports Medicine, 54(2), 3-5. doi: https://doi.org/10.1136/bjsports-2019-101253

Green, T., Willson, G., Martin, D., Fallon, F. What is the quality of clinical practice guidelines for the treatment of acute lateral ankle ligaments sprains in adults? A systematic review. BMC Musculoskeletal Disorders, 20(394), 1-13. doi: https://doi.org/10.1186/s12891-019-2750-6 
Gribble, P.A., Bleakley, C.M., Caulfield, B.M., Docherty, C.L., Fourchet, F. \& Fong D.T.P. (2016). Consensus statement of the International Ankle Consortium: prevalence, impact and longterm consequences of lateral ankle sprains. British Journal of Sports Medicine, 50(24),14931495. doi: https://doi.org/10.1136/bjsports-2016-096188.

Kerkhoffs, G., Bekerom, M., Elders, L., Beek, P., Hullegie, W., Bloemers, G., \& Bie, R. (2012). Diagnosis, treatment and prevention of ankle sprains: an evidence-based clinical guideline. British Journal of Sports Medicine, 46, 854-860. doi: https://doi.org/10.1136/bjsports-2011090490

LeFebvre, R., \& Hatch, S. (2016). Ankle Sprains: Management. Health Centers of UWS. Western States Chiropractic College.

Polzer, H., Kanz, K. G., Prall, W. C., Haasters, F., Ockert, B., Mutschler, W., \& Grote, S. (2012). Diagnosis and treatment of acute ankle injuries: development of an evidence-based algorithm. Orthopedic reviews, 4(1), e5. doi: https://doi.org/10.4081/or.2012.e5

Punt I.M., \& Allet L. (2016) Functional Effects of Ankle Sprain. In: Müller B. et al. (eds) Handbook of Human Motion. Springer, Cham. (pp.1-16). doi: https://doi.org/10.1007/978-3-319-308081_72-1

Roosen, P., Willems, T., De Ridder, R., San Miguel L., Holdt Hennigsen, K., Paulus, \& Jonckheer, P. (2013) Ankle sprains: diagnosis and therapy. Good Clinical Practice. Brussels: Belgian Health Care Knowledge Centre. KCE Reports 197C.

Scialoia, D., \& Swartzendruber, A. (2020). The R.I.C.E Protocol is a MYTH: A Review and Recommendations. The Sport Journal, 1-19.

Sousa, L.M.M., Marques-Vieira, C.M.A., Severino, S.S.P., \& Antunes, A.V. (2017). A metodologia de revisão integrativa da literatura em enfermagem. Revista Investigação em Enfermagem, 2(21), 17-26.

Souza, M.T., Silva, M.D., \& Carvalho, R. (2010). Integrative review: what is it? How to do it? Einstein, 8(1),102-6. doi: http://doi.org/10.1590/s1679-45082010rw1134

Vuurberg G., Hoorntje A., Wink L.M., Doelen B.F.W., Bekerom M.P., Dekker R., \& Kerkhoffs, G. (2018). Diagnosis, treatment and prevention of ankle sprains: update of an evidence-based clinical guideline. British Journal of Sports Medicine, 52(15), 956. doi: http://doi.org/10.1136/bjsports-2017-098106

Waterman, B.R., Owens, B.D., Davey, S., Zacchilli, M.A., \& Belmont, P.J. Jr. (2010). The epidemiology of ankle sprains in the United States. Journal of Bone and Joint Surgery. 6;92(13):2279-84. doi: http://doi.org/10.2106/JBJS.I.01537.

Wever, G.S. \& McCollum, G. (2018). The management of acute lateral ankle sprains: a survey of South African surgeons and best evidence available. The South African Orthopaedic Journal, 17(2), 35-39. doi: https://dx.doi.org/10.17159/2309-8309/2018/v17n2a6 